\title{
Anthós
}

\section{Social Constructions of Childhood: From Not-Yet- Adults to People in Their Own Right}

Sophia K. Biddle

Portland State University

Follow this and additional works at: https://pdxscholar.library.pdx.edu/anthos

Part of the Family, Life Course, and Society Commons Let us know how access to this document benefits you.

\section{Recommended Citation}

Biddle, Sophia K. (2017) "Social Constructions of Childhood: From Not-Yet-Adults to People in Their Own Right," Anthós: Vol. 8: Iss. 1, Article 3.

https://doi.org/10.15760/anthos.2017.10

This open access Article is distributed under the terms of the Creative Commons Attribution-NonCommercialShareAlike 4.0 International License (CC BY-NC-SA 4.0). All documents in PDXScholar should meet accessibility standards. If we can make this document more accessible to you, contact our team. 


\section{Social Constructions of Childhood:}

\section{From Not-Yet-Adults to People in Their Own Right}

Sophia K. Biddle

\section{Introduction}

Across the globe it is clear that children are a marginalized group. Children are not allowed to vote or be taken seriously in political circles (Sharpe, 2015), are kept away from public spaces (Valentine 2004), navigate inhospitable working conditions (Gamlin et. al., 2015), and are rapidly losing the time and space to foster their own child culture (Woolley and Griffin, 2014). Adults continue to institutionalize children's play and restrict children's access to public space. This serves to reinforce children's position as second-class citizens. A mounting body of work shows that children are suffering in their physical and social development due to this continued marginalization (Clements, 2004; Corsaro, 1997; Evaldsson, 1998; Goodwin, 1990; Staempfli, 2008). This naturalized and troubling dynamic between children and adults needs to be critically examined in order to foster a healthy, socially just society.

Drawing on literature from Corsaro, Valentine, and Goodwin I argue that "child" is the dominant identity for youth; their race, gender, and class following behind as important but secondary, intersecting identities. All children are oppressed. Different children experience this oppression to greater and lesser degrees. I argue that we must examine the social construct of childhood now, as societal ideals about children's rights, safety, and use of public space are rapidly evolving. A critical analysis of the state of childhood, which acknowledges the deeply entrenched oppression of children, sets the 
stage for a potential social transformation in which adult society can empower youth. Children already have legitimate, creative, and valid contributions to make to the societies they are a part of. By examining the social structures that serve to suffocate these contributions we can reconstruct the meaning of childhood. Adult culture can acknowledge children's voices and rights, thereby making childhood a time of empowerment rather than oppression.

Childhood is a global social construct rather than a static, wholly biological life stage (Valentine 2004). The social construct of childhood enables adults to justify their attempted control over children. Adults exercise this control by institutionalizing children, discrediting their social and political contributions, and marginalizing them from public space. I first provide a brief history of the evolution of western childhood, supporting my claim that the meaning of childhood evolves across history, and therefore is a social construct. I then pose Corsaro's constructivist model and concept of interpretive reproduction as the contemporary academic standard for understanding children's active influence on both their own child culture, and society at large. By examining children's use of language and space on a global scale I argue that children are already active social actors, rather than not-yet adults waiting to be molded into productive members of society. This body of evidence also demonstrates that childhood means different things to different societies, furthering the argument that childhood is a social construct. Lastly, I examine how the phenomenon of globalization is spurring a major shift in the concept of childhood. I argue that children's rights, voices, and contributions to culture should be genuinely 
acknowledged in order to form a diverse, strong, and healthy society. I conclude with the common youth advocacy theme, and that is: the radical notion that children are people.

\section{The Evolution of Childhood}

A solid historical analysis of childhood is crucial for understanding children as actively contributing to societal production and change, while simultaneously creating their own child cultures. The historical context of childhood in Western society is well documented, and shows a great variety in societal attitudes towards children (Aries, 1962; Corsaro, 1997; Valentine, 2004). During the Enlightenment period at the end of the $16^{\text {th }}$ century children started to be perceived as a separate social class from adults (Aries, 1962; Valentine, 2004). Aries' (1962) groundbreaking work on historical conceptions of childhood highlighted children's changing place in society. Aries noted a general movement from a lack of awareness of the idea of childhood, to a period where children were seen as a source of amusement for adults, to a moralistic period where childhood was seen as a time of training and discipline for adulthood. Aries attributes these shifts to changing institutional arrangements in European societies, such as the move towards more nuclear families and the emergence of age-graded schools (Aries, 1962). The clear evolution in societal attitudes regarding children is evidence that childhood is a social construct (Corsaro, 1997).

Historical studies of societal attitudes towards childhood also reveal an ongoing, tense dichotomy between Dionysian and 
Apollonian views of childhood. The Dionysian understanding of childhood views "children as a wildness" (Aries, 1962). This paradigm sees children as inherently sinful and positions children as beings that must be disciplined and socialized into "proper" adults (Valentine 2004). An Apollonian understanding of childhood states that children possess an inherent innocence and goodness that is somehow corrupted by the world they grow up in. Though these two perspectives of childhood appear to be entirely incompatible, both Dionysian and Apollonian paradigms lend themselves to adult-based control over children. Furthermore, both views are rooted in the assumption that children are broken, corrupted, and unworthy of full personhood. These paradigms place adults as the only source of salvation for children. The Dionysian paradigm assumes that children need adults in order to be saved from the child's own wildness. The Apollonian perspective assumes that children need adults in order to be shielded from the world at large. In both cases adults are positioned as the competent authority and children are positioned as powerless and inept.

The naturalization of adult-based control over children is prevalent in academic attitudes towards children and childhood. Well into the 1980's researchers viewed children as passive consumers of adult culture and therefore an invalid area of social research. Beginning in the late 1990's social scientists acknowledged the massive gap in sociological research regarding children. This gave rise to an academic era of examining children's contributions to society. The progressive, modern research approach to the sociology of childhood views childhood as a social construct and children as 
active social actors (Hunleth et. al. 2014; Jones, 2015; Jung, 2014; Zhang, 2013). Corsaro labels the previous academic attitudes as the "deterministic model" of childhood, in which society appropriates the child. In contrast, the "constructivist model" focuses on how the child appropriates society, wherein the child as a social actor manipulates society. The constructivist model uses the lens of interpretive reproduction to examine how children contribute to their own childhoods through negotiations with adults and creative production of their own child peer culture. This model argues that both children and adults participate in the social construction of all aspects of culture, including the construct of childhood (Corsaro, 1997). Corsaro argues that interpretive reproduction should not be viewed as a linear process. Instead, he argues that by viewing children's lives as active social actors on an orb-web model, rather than a linear model, we are better able to see a child's expanding, malleable, and fluctuating influence on all aspects of social life. Therefore, the orb-web model better accounts for the micro-level lives of individuals and the macrolevel concept of childhood.

The above studies collectively demonstrate the variety of changes that childhood has undergone throughout the centuries. Corsaro writes, "For children themselves, childhood is a temporary period. For society, on the other hand, childhood is a permanent structural form or category that never disappears even though its members change continuously and its nature and conception vary historically" (Corsaro, 1997). The evolving social attitude towards the phenomenon of childhood indicates that childhood itself is not a static, entirely natural life stage (Valentine 2004). Rather, children are 
active social actors who are always oppressed by the societies they are a part of. Combined, these historical studies have fostered a modern research agenda that is focused on children's collective actions and contributions to past societies. In the following section, I use the modern academic lens of the constructivist model to explore how children contribute to society at large and simultaneously generate their own child peer culture.

\section{Peer Culture}

Peer culture is the primary evidence for a unique and separate child culture. Peer culture is defined as a stable set of activities or routines, artifacts, values, and concerns that children produce and share in interaction with peers (Corsaro, 1997; Valentine 2004; Thorne, 1993; Opie and Opie, 1959). Consistent with interpretive reproduction, the concept of peer culture stresses children's collective actions, shared values, and participation in cultural production and social change. Preadolescent children's lore, games, verbal conflict routines, cross-gender play, and rituals typically address issues related to self-identity and autonomy from adult control (Corsaro, 1997; Thorne, 1993; Opie and Opie, 1959). Peer culture expands and evolves throughout childhood. A child's peer culture is affected by their families, adults, and the child's other social statuses; such as gender, race, and class.

Families play a key role in the creation of peer culture and interpretive reproduction (Corsaro 1997, Valentine 2004). Rather than individually experiencing input from the adult world, children collectively participate in cultural routines in which adults first 
mediate the information. Families often prepare children for entry into peer culture, in that parents arrange for and structure their children's early interactive experiences with peers, provide emotional support, and foster interpersonal styles. Additionally, parents introduce children to both symbolic and material aspects of children's culture. Parents introduce children to symbolic culture by encouraging and controlling children's access to media, literature, and mythical figures; material culture is introduced by purchasing cultural objects and by the level of encouragement parents provide for certain types of play. Children often extend and transform symbolic and material culture that they first attain in the family in their interaction with peers (Corsaro, 1997; Jones, 2015; Opie and Opie 1959). Once children move outside of the family, their activities with their peers establish a collective peer culture, which becomes just as important as children's interactions with adults.

Adults inherently affect children's peer cultures throughout childhood. Peer cultures arise and develop as a result of children's attempts to make sense of, and also resist, the adult world. Corsaro's ethnographic work in an Italian preschool captured this phenomenon first hand. When the head teacher prohibited playing with a large plastic carton, the preschoolers acted in direct opposition to the teacher's request. A group of preschoolers snuck away with the carton and transformed it into a flying bank that made house calls (Corsaro, 1997). I argue this defiance of adult authority, combined with the preschoolers' creative re-interpretation of the banking system, fundamentally supports the concept of interpretive reproduction and the constructivist model of childhood. The preschoolers' collective 
play is based in their understanding of the adult world, and the ways that the preschoolers can re-imagine it.

Peer culture thrives on children's play. Play serves as an avenue for establishing certain physical, commutative, and cognitive skills while also acting as an arena for addressing feelings, personal concerns, and uncertainties regarding peer relationships (Evaldsson, 1998; Jirata and Kjørholt, 2015). Issues of race and gender are actively interpreted by children and reproduced through play, language, and lore. In keeping with a constructivist model to the sociology of childhood, it is not surprising that children observe, experience, and absorb racial and gendered thinking, and apply it to their peer culture and play.

Many researchers assume that children do not have a concrete understanding of race until the ages of 7 or 8 . This assumption stems from the understanding that race is a more complex social construct than gender, and that racial and ethnic categories are not as clear-cut as the gender binary. Contrary to this assumption, Holmes (1995) found evidence that kindergarteners in the United States use skin color as a dominant identifying feature. Even among 5 and 6-yearolds, Holmes (1995) found that "White" appeared to be the default race. She observed that while White children rarely mention their skin color, Black children clearly stressed their dark skin (Holmes, 1995). Preschoolers clearly struggle with the nuanced concepts of race and ethnicity, but still attempt to root their identity in their ethnicity, and deploy ethnicity as a stratifying social marker in their play to exclude or include other children (Van Ausdale and Feagin, 2001). For example, Van Ausdale and Feagin (2001) observed Corinne, a biracial 
preschooler, proclaimed she was African. A new teacher informed Corinne, "Your mommy and daddy's ancestors came from Africa, but you are African American." Corinne retorted, "No, you don't get it, I'm from Africa. My daddy is from here" (Van Ausdale and Feagin, 2001). This preschooler is clearly attempting to make sense of the racialized social divisions in broader society. I argue this supports the constructivist model of childhood because Corinne is actively attempting to place her identity within the established, complex racial groups in adult culture. This attempt demonstrates her ability as an active social actor, indicating that children are capable of seeing and acting upon nuanced social phenomenon, such as race and ethnicity. Race, ethnicity, and gender often intersect and influence peer culture. Goodwin's 1990 research demonstrated varied linguistic patterns that correlated with the dominant ethnic identity of a peer group. Black children were found to deploy "he-said-she-said" talk as a mode of navigating conflicts, constructing social order, and negotiating personal identities (Goodwin 1990). Preadolescent peer culture within the predominately Black group of children used strong, confrontational language to challenge cultural missteps, such as talking behind one's back. Direct and purposeful language is also documented in Black children's regulation of rule following. 1 Goodwin's (1998) research compared Black girls' rule monitoring in games of hopscotch with that of White girls. Black girls typically

\footnotetext{
${ }^{1}$ Goodwin's 1998 case study shows Black girls deploying direct phrases when rules are in dispute. For example, when Lucianda was accused of hitting a line she proclaimed, "I ain't hit no line!" Alisha shouts back, "Yes, you did." After two other children agree with Alisha, Vanessa comes over to Lucianda and says, "You out now!"
} 
deployed direct phrases when rules were in dispute. In contrast to the strong language used in Black girls' peer culture, White girls commonly used passive, deferential language (Goodwin 1998). ${ }^{2}$ This case study demonstrated the correlation between varied linguistic patterns and race, even after gender is controlled for.

Goodwin's $(1990,1998)$ research on children's language and peer culture supports the argument that children do have real and legitimate social concerns, are socially savvy, and capable of implementing abstract problem-solving techniques to construct a social order. Linguistic variation between peer culture groups also supports the constructivist model of childhood. Children's peer cultures share the universal aspect of existing to defy adult control and generate a social network for children. On a micro-level, peer cultures vary widely depending on the race and gender of the children involved. Ultimately this research demonstrates that conflict and cooperation are often overlapping processes that are embedded in the larger ethos of playfulness. Numerous other studies support the idea that play is the medium through which children creatively negotiate personal conflict (Corsaro, 1997; Valentine 2004; Jirata and Kjørholt, 2015; Paksuniemi et. al., 2015). Non-verbal and verbal language is a critical building block to children's play. Language is deployed in all cultures as a method of generating social groups and boundaries, and children's culture is no exception to this phenomenon.

\footnotetext{
${ }^{2}$ When Lindsey hits a line with her foot, Kendrick clearly witnesses and shakes her head, saying "That's, I think that's sort of on the line though." Another girl chimes in saying, "Uh, your foot's in the wrong spot." Kendrick follows up with, "Sorry, that was a good try." And Lindsey was out of the game (Goodwin 1998).
} 
Children's language is used to subvert and mock adult authority, draw social borders within child culture, establish friendships, create a sense of belonging, demonstrate one's wit and intelligence, and transmit the values and beliefs of child culture itself (Goodwin, 1990; Opie and Opie, 1959; Thorne, 1993). The lore and language of school children is well documented in the European Union (Opie and Opie 1959). These findings fundamentally support the concept of interpretive reproduction and child peer culture. By following over 5,000 children across 70 schools during the 1950's the Opies recorded the plethora of ways that children have creatively repurposed the language of adult culture to create their own unique oral tradition of child-lore. The language that children use to regulate their relationships with each other can, in some places, be traced back through not just two or three generations, but for centuries. Established "dialectic lore" flows quietly yet much deeper than the slangy, superficial lore of catch phrases, jokes and comedic songs. Dialectic lore refers to what the Opies deem as children's "darker doings" such as sneaking, swearing, and tormenting. This is not to say children's songs and chants are crazes or fads. Rather, by examining historical data, the Opies found that after a 40 -year time span, $78 \%$ of "child-chants" were still in use. ${ }^{3}$

\footnotetext{
${ }^{3}$ By using the recordings of Norman Douglas in his work London Street Games (1916) the Opies found that of the 137 "child-chants" recorded by Douglas, 78\% were still being chanted by the children of Britain in 1956. Continuity in children's language was also demonstrated by a playground rhyme that evolved and has been passed down through generations of children since 1726. Lines from Henry Carey's 1726 ballad Namby Pamby were recorded in New York City in 1954 by children who used the lines as a jump-roping chant (Opie and Opie, 1959).
} 
By collecting empirical evidence of the continuity, creativity, and longevity of children's oral traditions, the Opies set the stage for discovering children's peer culture and methods of grappling with gender relations. Thorne's (1993) study on borderwork, activities that mark and strengthen boundaries between groups, heightened awareness about the complexity of gender relations within child culture. This phenomenon within child culture occurs when children evoke both verbal and non-verbal language to draw social boundaries. Throne identified three modes of gender specific borderwork: contests, chases, and invasions. Chases and invasions both establish and/or enforce male dominance in social interactions (Thorne, 1993). Thorne observed that children's language served to differentiate between same-gender and other-gender chase games. Specifically Thorne found that only other-gender chase games were named. Kids call these games "girls-chase-the-boys," "catch-and-kiss," or "kiss-orkill." These chasing games act as a stage for children to practice "doing" gender. When children discuss these games, gender terms override any individual identities in reference to what Thorne calls "the other team." For example, provocation of a chase game would begin with a phrase like, "C'mon Sarah, let's get that boy" (Thorne, 1993). This ongoing process of borderwork in play creates a space for girls and boys to interpret, mold, and reconstruct gender roles (Thorne, 1993).

Studies conducted by Goodwin, Thorne, and Evaldsson empirically support the constructivist model of childhood by demonstrating children's ability to grapple with complex and nuanced topics such as gender and race through play and interaction with their 
peer culture. By claiming space and language for themselves, kids fully demonstrate their ability to interpret the adult world and creatively reconstruct it. This process also separates children from adults. The existence of child-lore and language serves as a type of borderwork between adult and child cultures. Therefore, we can see that children themselves contribute to the social construction of childhood by perpetuating peer culture.

\section{Disempowering Children}

Adult culture controls and further marginalizes children by barring them from voting or seriously participating in democratic governance, systematically denying them access to public space, and institutionalizing their play. Youth governance programs are increasing in number, but not increasing their influence (Sharpe 2015). In most, if not all, democratic societies, youth are unable to vote in political elections. In addition to scarce political rights, children are increasingly losing the right to inhabit public space. Curfews and anti-loitering laws serve to criminalize teenager's use of public space. Parents who allow younger children to walk in public space without adult supervision can now face neglect charges, therefore disincentivizing parents to allow their children any sense of independence in outdoor public space (McCarren, 2015). Children's play is being forced into various institutions such as schools, organized sports, conservatory art courses, and after-school care programs. Youth's lack of political pull to combat the restricted access to public space is problematic. Children's play, and therefore children's peer cultures, are becoming increasingly contingent upon 
families' ability to pay for adult organized activities. This means that children's peer cultures are shrinking (Woolley and Griffin, 2014) and becoming increasingly divided by socioeconomic class (Valentine, 2004; Woolley and Griffin, 2014). Children's rapidly decreasing access to public space, and severe lack of political power, must be critically examined. The current trends of criminalizing and stigmatizing youth's access to public space only serves to enforce social strata based on socioeconomic class, and to further subjugate children to the will of adults.

Valentine (2004) argues that "socio-spatial marginalization is a feature of western childhoods." However, Katz's (1998) research compared the geographies of teenage girls in New York City and Sudan, and ultimately concluded that both groups of girls are equally restricted by their cultures in the use of public space, though the cultural reasons are superficially different. Well-meaning parents are often the primary barriers for children to negotiate in order to access open, flexible, and public play space. A significant body of literature ties the rise in parent anxieties to the rise in globalized and 24-hour news media stoking the fire of stranger-danger narratives (Valentine, 2004; Villanueva et. al., 2014; Woolley and Griffin, 2014). Strangerdanger discourses and increased global reporting of violent crimes against children, also called "terror talk," are primary contributors to parent anxieties. The occurrence of this public discourse may, and most likely does, distort local fears by heightening parents' awareness of extreme and rare events causing them to restrict their children's movement in public space. As people's knowledge of the world expands, children's access to the world contracts (Valentine, 2004). 
Stranger-danger discourse also serves to keep children from intruding upon the adult-dominated public space. This discourse is used as a means for controlling children, keeping them in the home and reducing their independence and autonomy.

Woolley and Griffin's (2014) research produced findings that mapped the rise in terror talk with the decline in children's access to outdoor public play space across three generations in Northern England. Three types of home range, "the distance children travel away from their home in the course of their outdoor play and leisure pursuits" (Mathews, 1992), were identified: habitual/ free range, range with permission, and range with permission and with other children (Hart, 1979). In the process of mapping changing home ranges, one family showed that in the span of three generations children went from an independent home range of $3 \mathrm{~km}$ to a nonexistent independent home range. Woolley and Griffin (2014) found that interviewees who were children in the late 1920's and early 1930's reported habitual free range with cohorts of approximately 20 children (Woolley and Griffin, 2014). In contrast, contemporary children only experience habitual free range with one or two other children. Interestingly, children across generations defy parent restrictions on home range (Woolley and Griffin, 2014). I argue that this historical continuity regarding children's resistance to adult-based control supports the claim that children are a socially active, marginalized population rather than passive consumers of the adult society around them. Even as home range has transitioned from a negotiation to an adult-based imposition, children continue to find ways to subvert adult rules and assert independence and autonomy. 
Restricted home ranges and parent anxieties are unproductive in the process of providing children with safe outdoor play spaces and teaching children how to competently evaluate threatening situations (Valentine, 2004). The dynamic of authoritative adults placing unreasonable and unexplained restrictions on children's independence and autonomy creates relationships where children are less likely to share experiences that felt unsafe with their parents (Valentine, 2004). Children report that informing their parents of these experiences will cause the children to be restricted in their use of public space or cause parents unnecessary anxiety (Valentine, 2004; Woolley and Griffin, 2014). Kids will instead turn to their peers for help in navigating a threat in public space and often handle the situation competently. Children develop plans to travel in groups, predetermine their routes and the locations of available adults who could help in an emergency, and are quick to leave situations in which they feel unsafe (Valentine, 2004). Despite evidence that children are capable of handling themselves in public, along with evidence that children are more at risk of harm in private spaces rather than public spaces (Corsaro, 1997; Valentine, 2004; Woolley and Griffin, 2014), popular discourse continues to enforce the marginalization of youth in public space in the name of children's safety.

As children are kept from public play space by their parents, children's peer cultures are being forced to organize outside of and around adult supervised institutions such as school, club sports, scouts, and conservatory arts courses. The institutionalization of children's play limits children's exposure to an array of cultural and socioeconomic backgrounds, and decreases the size of their peer 
groups significantly (Woolley and Griffin, 2014). Socioeconomic status heavily influences a child's ability to participate in extracurricular activities in particular (Valentine 2004). As access to peer culture becomes contingent upon family finances, children's peer culture inherently becomes more stratified along the lines of socioeconomic class and race. While children from working-class families are more likely to have access to unsupervised outdoor play than their wealthier counterparts, this is a mixed blessing. Working class children can, in theory, have greater access to the benefits of flexible outdoor play (Clements, 2004; Corsaro, 1997; Evaldsson, 1998; Goodwin, 1990; Staempfli, 2008). The reality for working class children's play space is more complex, given that parents from all socioeconomic backgrounds express deep dissatisfaction with the quality of outdoor, public play space for their children. ${ }^{4}$ One of the attractions of outdoor play is that children are able to appropriate and reclaim adult space for themselves. "Flexible" play spaces are by far the preferred play space for children ages 8-13, as opposed to factory made playgrounds and indoor add-on play areas (Valentine, 2004; Woolley and Griffin, 2014). Children often name places after the way they use them, thereby making themselves at home in public space (Valentine, 2004). This again points to children as active social actors who interpret and reconstruct both child and adult cultures.

\footnotetext{
${ }^{4}$ Valentine (2004) found that $91 \%$ of working class parents and $70 \%$ of middleclass families feel that their neighborhoods have unsatisfactory play spaces (Valentine, 2004). 


\section{Globalization: Changing Childhood}

Globalization is spurring a large transition in the meaning of childhood in what is being referred to as the global south, Africa, Latin America, and developing Asia including the Middle East. Cultural ideas of childhood in the rural, global south are often at odds with those of wealthier and urban parts of Northern Europe and the United States. The United Nations has called for all children to enroll in, and complete, primary school (Hunleth et. al., 2014; Jirata and Kjørholt, 2015). Children in rural areas are now being asked to balance school with the domestic labor their families rely on them for. The domestic labor these children perform is often considered a critical aspect of childhood within their local cultures. Work and play are combined and create a space for children to learn local knowledge and solidify their connections to family and friends (Jirata and Kjørholt, 2015; Zhang, 2013). In much of the global south and in rural areas across the globe the domestic renewal labor performed by children is pivotal to the survival of the family (Zhang, 2013). By imposing western education standards without consideration for the cultural importance of children's work, or the economic conditions that result in children entering the labor force, the U.N. is perpetuating the dismissal of children's contributions to their families and societies.

New western education standards are the primary way that globalization is changing childhood in the global south. The United Nation's call for all children to complete primary school is based in an agenda to end child labor and provide children with opportunities for upward mobility in an increasingly globalized culture. Though 
well intentioned, westernized education standards often ignore the gravity of economic, social, and cultural circumstances that lead to children entering the labor force. Recent policy research conducted for the U.K. Department for International Development has attempted to balance western ideals of childhood as a responsibility-free time with the economic reality many children face, in order to construct practical, ethical child labor ${ }^{5}$ practices. Domestic labor is a common source of employment and, at times, exploitation for children. Of the estimated 52 million child laborers world wide, approximately 44 million of them are girls (Gamlin et. al., 2015); girls overwhelmingly perform domestic labor tasks, with only $10 \%$ of the child domestic laborers being male. Policy writers in the U.K. and the U.N. are aware that banning domestic work could force children into even more dangerous jobs, while also balancing the likelihood of child laborers possibly facing extreme abuse and exploitation in their often private place of domestic work (Gamlin et. al., 2015). Gamlin et. al. (2015) argue that domestic labor is not inherently harmful, and is perhaps ultimately safer, than other forms of work. Researchers acknowledge that domestic work is a complex occupation that requires better social and political support in order to ensure the safety and rights of child laborers (Gamlin et. al., 2015; Sharpe, 2015).

Globalization's impact on childhood is also evident in developing urban areas such as Hong-Kong. Similar to conceptions of childhood in the U.S., children in middle-class Hong-Kong culture are

\footnotetext{
${ }^{5}$ Child labor is defined as "work that deprives children, ages 5-17 of their childhood, their potential and their dignity and that is harmful to physical and mental development" (Gamlin et. al., 2015).
} 
seen as objects to be molded into successful adults (Karsten, 2014). Hong-Kong childhood also requires children to sacrifice unsupervised playtime in order to shoulder intensely busy schedules to keep up with the increasingly globalized job market and education standards (Karsten, 2014). This dynamic makes Hong-Kong childhood similar to the changing childhood in the global south. However, the responsibilities of children in the global south focus on basic survival, and the children are often unsupervised, thus allowing opportunities for spontaneous play. These are key distinctions that are not present in the lives of middle-class children in Hong-Kong (Karsten, 2014). The children in middle-class Hong-Kong appear to operate within an adult culture that blends Dionysian and Apollonian views of childhood. Children are heavily monitored and restrained in order to be molded into successful adults, while also being sheltered from the broader world around them. This emerging combination of Dionysian and Apollonian paradigms is a result of globalization, as middle-class Hong-Kong attempts to keep pace with standards set by the United States and the European Union. Across these studies, it is crucial to note that children continue to play. Children from migrant families in China (Zhang, 2013), farming families among the Guji in Ethiopia (Jirata and Kjørholt, 2015), the far-reaching kinship connections in Zambia (Hunleth et. al., 2014), and the dense urban environment of Hong-Kong (Karsten, 2014), find opportunities for "playful learning" or playful work (Karsten, 2014). This directly relates to Corsaro's constructivist model of interpretive reproduction. Children find ways to pass stories, songs, and wisdom to each other across a vast variety of geographic settings. Despite the rising pressures of globalization, 
children continue to audaciously appropriate spaces, language, and knowledge for their own use and amusement across most, if not all, societies.

\section{Conclusion}

Further studies incorporating participatory research methods are needed in order to combat the systemic marginalization of youth. Sharpe (2015) points out that truly productive policy research that aims to empower youth must incorporate the voices of all children, including those who are in juvenile detention facilities, from low socioeconomic backgrounds, disabled, part of ethnic minority groups, and of all genders. Currently, Sharpe (2015) finds that participatory policy research with youth frequently focuses on high-achieving "adult-like" children and still is not seriously considered by adult legislators and policy makers. Despite being largely dismissed by the adult-dominated political system, a number of youth government organizations have not been deterred from lobbying for reasonable changes to public space in order to make the space more accessible for children. These requests are real and legitimate, and include a lower youth public transit fare, greater investment in and better access to youth centers, and youth-focused workers in public hospitals (Sharpe, 2015). I argue that by practicing participatory research methods we can genuinely listen to and incorporate children's voices into public policies that better allow children to claim their rights. All people have the right to participate in governance, work in good conditions, and safely use public space. Critically examining and dismantling the naturalized power dynamic between children and 
adults leaves us with the radical notion that children are people too, and thereby entitled to these same rights.

In this paper I have demonstrated that children face systemic oppression across cultures. Children combat this oppression by formulating unique child peer cultures, which allow children to subvert adult authority, navigate personal identities and relationships, and creatively interpret the world around them. All children are oppressed. Different children experience this oppression to greater and lesser degrees. Gender, race, socioeconomic status, geographic location and local social norms all heavily color an individual's experience of childhood. I have argued that "child" is the dominant identity for youth; their race, gender, and class following behind as important but secondary, intersecting identities. It is vital to remember that this discussion is about the very real experience of childhood. Childhood is a social construction enforcing the systemic marginalization of youth, creating very real consequences for both individuals and society at large. Valentine argues, and I wholeheartedly agree, that we need to move away from seeing children as a problem that must be contained, or corralling children for their own safety. We must stop generating policies to further institutionalize children; instead we need to focus on children's rights. Children have the right to use public space, work, participate in governance, and play safely just as adults do. In order to create equitable, unbiased, and compassionate societies we must acknowledge children's inherent personhood. 


\section{References}

Aries, P. (1962). Centuries of childhood: A social history of family life (p. 315).

New York: Vintage Books.

Clements, R. (2004). An investigation of the status of outdoor play. Contemporary issues in early childhood, 5(1), 68-80.

Corsaro, W. A. (1997). The sociology of childhood (pp. 4-5). Thousand Oaks, CA: Pine Forge Press.

Evaldsson, A. C., \& Corsaro, W. A. (1998). Play and Games in the Peer Cultures of Preschool and Preadolescent Children An Interpretative Approach. Childhood, 5(4), 377-402.

Gamlin, J., Camacho, A. Z., Ong, M., \& Hesketh, T. (2015). Is domestic work a worst form of child labour? The findings of a sixcountry study of the psychosocial effects of child domestic work. Children's Geographies, 13(2), 212-225.

Goodwin, M. H. (1990). He-said-she-said: Talk as social organization among black children (Vol. 618). Indiana University Press.

Goodwin, M. H. (1998). Games of stance. In Kids talk: Strategic language use in later childhood (pp. 23-46). Oxford University Press Oxford.

Hart, R. (1979). Children's experience of place. Irvington.

Hunleth, J., Jacob, R., Cole, S., Bond, V., \& James, A. (2015). School holidays: examining childhood, gender norms, and kinship in children's shorter-term residential mobility in urban Zambia. Children's geographies, 13(5), 501-517.

Jirata, T. J., \& Kjørholt, A. T. (2015). The place of children among the Guji of southern Ethiopia: school, work and play. Children's Geographies, 13(2), 226-239.

Jones, S. A. (2015). Children Reading Series Books: Ways into Peer Culture and Reading Development. Changing English, 22(3), 307325.

Jung, J. K. (2015). Community through the eyes of children: blending child-centered research and qualitative geovisulization. Children's Geographies, 13(6), 722-740.

Karsten, L. (2015). Middle-class childhood and parenting culture in high-rise Hong Kong: on scheduled lives, the school trap and a new urban idyll. Children's Geographies, 13(5), 556-570. 
Katz, C. (1998). global economic restructuring and the eroding of ecologies of youth1. Cool places: Geographies of youth cultures, 130144.

Matthews, M. H. (1992). Making sense of place: Children's understanding of large-scale environments. Barnes \& Noble Books.

McCarren, A. (2015, April 13). Parents in trouble again for letting

kids walk alone.

Opie, I., \& Opie, P. (1959). The language and lore of schoolchildren.

Paksuniemi, M., Määttä, K., \& Uusiautti, S. (2015). Childhood in the shadow of war: filled with work and play. Children's Geographies, 13(1), 114-127.

Sharpe, D. (2015). Young people's involvement in policy research. Children's Geographies, 13(2), 240-248.

Staempfli, M. B. (2008). Reintroducing adventure into children's outdoor play environments. Environment and Behavior.

Thorne, B. (1993). Gender play: Girls and boys in school. Rutgers University Press.

Valentine, G. (2004). Public space and the culture of childhood. Aldershot: Ashgate.

Villanueva, K., Giles-Corti, B., Bulsara, M., Trapp, G., Timperio, A., McCormack, G., \& Van Niel, K. (2014). Does the walkability of neighbourhoods affect children's independent mobility, independent of parental, socio-cultural and individual factors?. Children's Geographies, 12(4), 393-411.

Woolley, H. E., \& Griffin, E. (2015). Decreasing experiences of home range, outdoor spaces, activities and companions: changes across three generations in Sheffield in north England. Children's Geographies, 13(6), 677-691.

Zhang, N. (2015). Home divided, home reconstructed: children in rural-urban migration in contemporary China. Children's Geographies, 13(4), 381-397. 